\title{
The Role of Balloon Sinuplasty in the Treatment of Vacuum Rhinogenic Headache
}

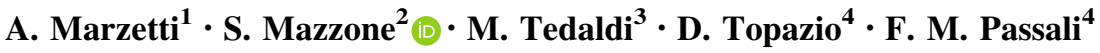

Received: 17 March 2016/Accepted: 25 January 2017/Published online: 3 February 2017

(C) Association of Otolaryngologists of India 2017

\begin{abstract}
In this study we tried to demonstrate how balloon sinuplasty could be an option in the treatment of the Rhinogenic Headache due to a probably disventilation of frontal sinus recess. 107 patients were included in the study with diagnosis of Rhinogenic Headache. The surgical group underwent bilateral balloon sinuplasty of the frontal sinus. The medical group underwent pharmacological treatment. Headaches characteristics were evaluated by a clinical personal diary. The severity was recorded by Visual Analog Scale 4 and 8 months after treatment. 98 out of 107 patients completed the protocol. In surgical group and in medical one the mean headache score improved at four and eight months follow up. The headache frequency attacks per month decrease from a preoperative frequency of 18 ( $\pm 4 \mathrm{SD})$ in surgical group and 17 ( $\pm 3 \mathrm{SD})$ in medical
\end{abstract}

S. Mazzone

sara.mazzone1@gmail.com

A. Marzetti

andreamarzetti06@gmail.com

M. Tedaldi

massimiliano.tedaldi@yahoo.it

D. Topazio

davide.topazio@libero.it

F. M. Passali

passali@med.uniroma2.it

1 Head and Neck Surgery Division, San Carlo Hospital, Rome, Italy

2 Head and Neck Surgery Division, San Camillo-Forlanini Hospital, Rome, Italy

3 Maxillo Facial Surgery Department, University of Rome "La Sapienza", Rome, Italy

4 Ent Clinic, Department of Surgical Sciences, University of Rome "Tor Vergata", Rome, Italy group to $3( \pm 1 \mathrm{SD})$ and $6( \pm 3 \mathrm{SD})$ respectively at 4 months control but increased slightly to $5( \pm 2 \mathrm{SD})$ and 12 ( $\pm 4 \mathrm{SD})$ after 8 months. We concluded that the balloon sinuplasty should be considered as an effective alternative option after an accurate selection of surgical candidates. However, it is important a 6-8 month follow-up to evaluate the efficacy and stability of the treatment used.

Keywords Rhinogenic headache · Balloon sinuplasty · Vacuum headache $\cdot$ Frontal sinus variations

\section{Introduction}

Headache is a very common condition that affects at least $80 \%$ of the population, defined as a pain with a predominantly neurocranial location whose topographical extension does not correspond to the territory of distribution of single nerve trunks. It has a great range of etiological factors: primary headache is an idiopathic form and etiological factors are not detectable (migraine, tension type headache, cluster headache), secondary forms can have systemic or local causes [1]. Therefore, the headache is a disease that must be well investigated and requires a multi-specialist collaboration.

In the contest of secondary headache, some common causes, such as acute and chronic rhinosinusitis, anatomical variations and sinonasal lesions, requires otolaryngology evaluation [2].

Rhinogenic Headache (RH) is a secondary form of headache, described as a facial pain syndrome in the absence of inflammatory sinonasal disease, purulent discharge and sinonasal polyps or masses, caused by mucosal contact points in the sinonasal cavities [3, 4]. In 1948 Wolf reported that the stimulation of the nasal septum and 
middle turbinate, both innervated by anterior ethmoidal nerve, a branch of the ophthalmic division of the trigeminal nerve, caused pain in the medial canthus area of the supraorbital region [5]. In 2004, mucosal contact headache was added as a secondary headache disorder in the International Classification of Headache Disorders [6].

Primary headache is often confused with RH due to their similar location and manifestation. Therefore, before treating patients, it is important to differentiate true $\mathrm{RH}$ from migraine, cluster and tension-type headache and it is necessary to exclude inflammatory sinonasal diseases or masses.

In the last 20 years, several authors have described the effectiveness of Endoscopic Sinus Surgery (ESS) in the treatment of $\mathrm{RH}$ but the role of ESS remains debated because of difficulty of identifying the real cases of $\mathrm{RH}$ $[7,8]$.

According to Yarmohammadi (2011) the diagnosis of rhinogenic headache is made by exclusion that requires a high index of suspicion, the Lidocaine Test must confirm anterior rhinoscopy and diagnosis [9, 10]. Mariotti (2009) and Roozbahany (2013) shown that the Computerized Tomography findings plays a very important role in the diagnosis of $\mathrm{RH}$ and allows to recognize the anatomical variations and contact points involved in the genesis of headache. The surgical treatment should be personalized for every patient considering the individual anatomical variations [11, 12].

However, Sanges in 2011 described a real correlation between headache and fronto-turbinalis expansion and demonstrated the effects of these anatomical variations on the mucosa and on the intra-sinusal pressure [13].

The purpose of our study was to examine further rhinogenic headache comparing the effect of conventional medical therapy and the balloon sinuplasty, recently introduced as a minimally invasive surgery for dilatation of the frontal sinus drainage pathways, and to identify other factors that may be involved in the benefit from surgical approach.

\section{Methods}

One thousand and two hundred and ten consecutive patients from 2012 to 2015 arrived to ENT clinic of San Carlo Hospital in Rome by neurology department for headache with no clear causes. All patients previously underwent a complete evaluation by ophthalmologist, neurologist, internist or any other related specialist and treated by different medications or other conservative treatment without headache resolution.

In our clinic, all patients underwent anamnesis, ENT examination with nasal endoscopy performed by a $2.7 \mathrm{~mm}$ 0-degree rigid endoscope and CT scanning of nose and sinuses with assial, coronal and sagittal projections to recognize inflammatory sinonasal diseases or the presence of anatomical variations and contact point. In 1000 patients, inflammatory sinonasal diseases, such as nasal polyps, hyperplastic mucosa or mucopurulent discharge, were recognized and so these patients were excluded from the study as reported in a previous study [14].

On two hundred and ten patients without signs of inflammatory disease, topical anaesthetic test was performed by an application of cotton pledgets soaked in xylocaine $10 \%$ (lidocaine $10 \mathrm{mg}$ ) with adrenaline (epinephrine, 1:200,000) into the nasal cavities, to evaluate the rhinogenic headache origin. Visual Analog Scale (VAS) Questionnaire for subjective assessment of symptoms was recorded before and after this procedure. We have considered positive Lidocaine test when it shown more than $50 \%$ relief of the headache after $15 \mathrm{~min}$.

One hundred and three patients were excluded from the study for negativity of Lidocaine test and for the presence of abnormal septum deviation, inferior turbinate's contact points or for uncertain headache origin.

Finally, 107 patients (45 male, 62 female) were included in the study with diagnosis of RH.

We divided 107 patients in two groups: the surgical group and the medical one. In the surgical group were included 52 patients who underwent surgical treatment of bilateral balloon sinuplasty of the frontal sinus. In the medical group were included 55 patients who refused surgical planning and underwent pharmacological treatment with three cycles of topical corticosteroids, alternating one month of continuous therapy with 15 days of no therapy. The hypertrophy of inferior turbinate was treated by oral or topical decongestant in medical group and by decongestion with Coblator technique in surgical group.

Each patient of both groups has reported on its own clinical personal diary frequency and duration of episodes of headache after the beginning of the study. Moreover, the severity of headache was recorded by 0-10 Visual Analog Scale (VAS) at baseline and 4 and 8 months after treatment.

Informed consent was obtained from all individual participants included in the study.

Statistical analysis was performed by comparing the data of Surgical Group and Medical Group at baseline evaluation and after 4 and 8 months after treatment. All data were analysed using Stata SE 10.1 System. $T$ test was used for the evaluation of variables means in each group. Analysis of correlation was done through Spearman correlation method. The values were evaluated using descriptive statistical methods (mean \pm SD) and the results were expressed at a significance level of $p<0.05$. 
Table 1 Distribution of anatomic variations of frontal region

\begin{tabular}{lll}
\hline $\begin{array}{l}\text { Frontal pneumatization } \\
\text { pattern }\end{array}$ & $\begin{array}{l}\text { Surgical group } \\
(\mathrm{N}=48)\end{array}$ & $\begin{array}{l}\text { Medical group } \\
(\mathrm{N}=50)\end{array}$ \\
\hline Agger nasi cell & 12 & 14 \\
Frontal cell type 1 & 8 & 6 \\
Frontal cell type 2 & 4 & 5 \\
Frontal cell type 3 & 4 & 2 \\
Frontal cell type 4 & 0 & 3 \\
Supraorbital ethmoid cell & 6 & 7 \\
Frontal bullar cell & 2 & 2 \\
Suprabullar cell & 3 & 2 \\
Interfrontal sinus septal & 2 & 0 \\
$\quad$ cell & & 9 \\
Recessus terminalis & 7 & \\
\hline
\end{tabular}

\section{Results}

Ninety-eight (91.5\%; 40 male, 58 female, mean age $42 \pm 3$ years) out of one hundred and seven patients completed all pre-treatment and post-treatment protocol (48 Surgical Group, 50 Medical Group). No significant post-operative or post medical treatment complications were recorded in both groups.

No statistically significant differences there were between two groups in demographic or disease severity parameter used in this trial.

Table 1 shows CT scans results and distribution of different anatomic variations of frontal region in surgical group and medical one.

The mean VAS score on headache severity globally improved in all patients with a statistically significant reduction in the subjective headache after both surgical and medical treatment $(p<0.0001)$. In particular, preoperative mean VAS score was $6.1( \pm 0.8 \mathrm{SD})$, and $0.9( \pm 0.6 \mathrm{SD})$ and $1.5( \pm 0.9 \mathrm{SD})$ after 4 and 8 months respectively (Fig. 1).

In surgical group, the mean preoperative headache score was $6.1( \pm 0.8 \mathrm{SD})$ and it improved to a 4 months control score of $0.6( \pm 0.4 \mathrm{SD})$ and to a 8 months control score of 0.7 ( $\pm 0.4 \mathrm{SD})$. In medical group, the mean pre-treatment headache score was $6.2( \pm 0.8 \mathrm{SD})$ and it improved to a 4 months control score of $1.2( \pm 0.5 \mathrm{SD})$ to an 8 months control score of $2.2( \pm 0.5 \mathrm{SD})$. We compared the mean post-treatment headache score at 8 months control in medical group was larger compared with surgical group $(p<0.05)$ (Fig. 2) (Table 2).

The headache frequency attacks per month decrease from a preoperative frequency of $18( \pm 4 \mathrm{SD})$ in surgical group and $17( \pm 3 \mathrm{SD})$ in medical group to $3( \pm 1 \mathrm{SD})$ and 6 ( $\pm 3 \mathrm{SD}$ ) respectively at 4 months control but increased slightly to $5( \pm 2 \mathrm{SD})$ and $12( \pm 4 \mathrm{SD})$ after 8 months (Table 3).

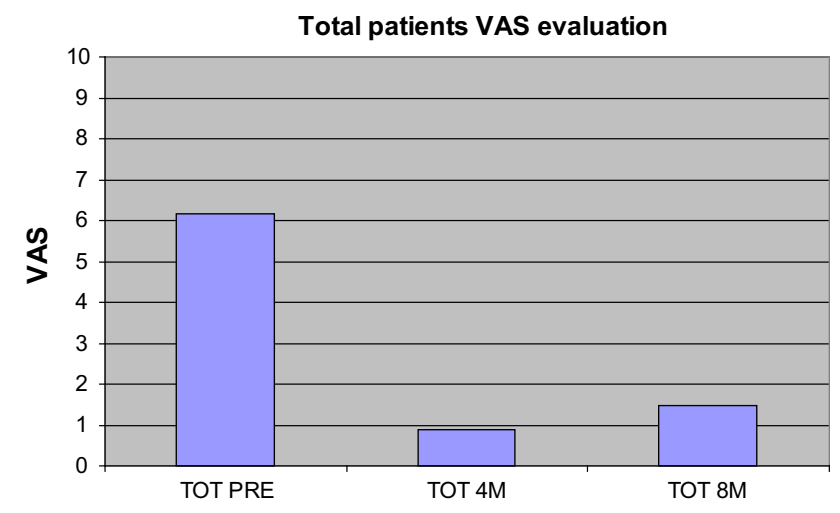

Fig. 1 Total patients VAS evaluation for headache severity

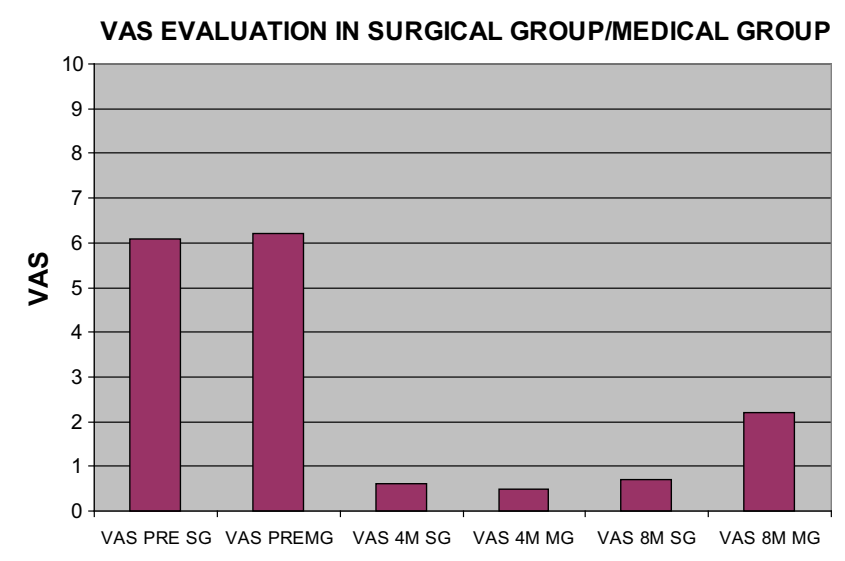

Fig. 2 VAS evaluation of headache severity in surgical group and in medical group pre-treatment, at 4 months follow-up, at 8 months follow-up

Table 2 VAS score of headache severity

\begin{tabular}{llll}
\hline & $\begin{array}{l}\text { Surgical group } \\
(\mathrm{N}=48)\end{array}$ & $\begin{array}{l}\text { Medical group } \\
(\mathrm{N}=50)\end{array}$ & $p$ value \\
\hline Pre-treatment & $6.1( \pm 0.8 \mathrm{SD})$ & $6.2( \pm 0.8 \mathrm{SD})$ & $>0.05$ \\
After 4 months & $0.6( \pm 0.4 \mathrm{SD})$ & $1.2( \pm 0.5 \mathrm{SD})$ & $>0.05$ \\
After 8 months & $0.7( \pm 0.4 \mathrm{SD})$ & $2.2( \pm 0.5 \mathrm{SD})$ & $<0.05$ \\
\hline
\end{tabular}

Table 3 Headache frequency attacks for months

\begin{tabular}{lccc}
\hline & $\begin{array}{l}\text { Surgical group } \\
(\mathrm{N}=48)\end{array}$ & $\begin{array}{l}\text { Medical group } \\
(\mathrm{N}=50)\end{array}$ & $p$ value \\
\hline Pre-treatment & $18( \pm 4 \mathrm{SD})$ & $17( \pm 3 \mathrm{SD})$ & $>0.05$ \\
After 4 months & $3( \pm 3 \mathrm{SD})$ & $6( \pm 3 \mathrm{SD})$ & $>0.05$ \\
After 8 months & $5( \pm 2 \mathrm{SD})$ & $12( \pm 4 \mathrm{SD})$ & $<0.05$ \\
\hline
\end{tabular}

In medical group, 17 patients reported a symptoms worsening during each medical therapy suspension period and after 8 months. Two patients of surgical group referred a worsening of intensity and recurrence of headache attacks at 8 months control. 
We have not found any significant correlation between demographical data and other parameters evaluated. There was no significant correlation between different anatomical variations and response to surgical or medical treatment.

\section{Discussion}

In the last few years one of the ESS hallmarks has been a minimally invasive technique with maximal mucosal preservation, the same goal has been achieved recently by the continuous introduction of new innovative instrumentation like Balloon Catheters, whose benefits have already been demonstrated in surgical treatment of rhinosinusitis by several studies $[15,16]$.

In our previous study, we showed how balloon sinuplasty could be useful in the treatment of rhinosinusitis but also in Sinus Headache. In this paper we tried to demonstrate how balloon sinuplasty could be an option in the treatment of Rhinogenic Headache due to a probably disventilation of frontal sinus recess. Previous authors have demonstrated that, in absence of paranasal disease, the referred headache often results from pressure on the nasal mucosa probably modified by anatomical variations. It has been hypothesized that Rhinogenic Headache may results from the activation of nociceptors localized in nasal mucosa. Probably, the high pressure on the nasal mucosa is associated with changes in the vascular supply, ending in the release of biological markers like $\mathrm{P}$ substance that stimulate the polymodal receptors that are innervated by different $\mathrm{C}$ fibres of ophthalmic and maxillary branches of trigeminal nerve $[17,18]$. Chow demonstrated that various anatomical variations could cause headache in absence of sinus inflammations [7].

Sluder, in 1997, popularized the concepts of vacuum headache. He described the phenomenon as barometric pressure changes affecting narrow drainage pathways of sinus, resulting pain over the involved sinus without disease [19]. According to this theory, the re-establishment of the physiological ventilation of paranasal sinus may be decisive in handling cases of suspected vacuum rhinogenic headache.

Indeed, Bolger described all sinuses anatomical variations and described different types of middle turbinate pneumatisation. According to Roozbahany, in the RH genesis, the most common anatomical abnormalities were middle turbinate concha bullosa and lamella bullosa, a pneumatisation of vertical lamella of middle turbinate for their effect on the ventilation frontal sinus recess [20, 21].

Kuhn described prevalence of frontal recess pneumatisation patterns in patients with no history of frontal sinus disease and recently describe the benefits of balloon sinuplasty of frontal recess in patients with frontal sinus disventilation [15].
Concha bullosa could be a main cause of referred headache if associated with another anatomical variation such Haller cell. The incidence of Haller cell in the general population is variably reported as $10 \%$ (Kennedy) [22] and $45 \%$ (Bolger) [20] and it can block the infundibulum and the sinus drainage pathway, resulting in vacuum or pressure headache.

In these patients, the opening of infundibulum corrects the positive pressure gradient allowing equilibrium with atmospheric pressure.

According to vacuum headache theory, initial treatment aim is to reduce mucosal edema and compression. The effectiveness of functional endoscopic surgery for headache treatment is different in papers and probably this could be mainly related to the patients' selection criteria. Based on our experience, we proposed surgical treatment with balloon sinuplasty after a complete clinical evaluation and failure of medical therapy [14]. We included in our evaluation the patients according to a positive xylocaine test. However, the clinical and diagnostic criteria do not allow an unambiguous interpretation of the data, and the improvement of the headache with the test to xylocaine cannot guarantee an adequate selection of patients.

In our study, we observed an overall improvement in rhinogenic headache in medical group and in surgical one. However, in both groups despite the improvement observed at 4 months follow-up, we observed a further worsening of symptoms at 8 months follow-up. Thus, to evaluate the efficacy and stability of the medical and surgical treatment of a rhinogenic headache, it is necessary to observe appropriately the patients for at least 6-8 months. Two of our patients developed headache again after 8 months and probably the synechiae of frontal recess could be an unlikely cause for this recurrence. On the other hand, 17 patients of medical group referred a worse of symptoms at 8 months control.

\section{Conclusion}

According to the vacuum rhinogenic headache, possible contact point or other causes involved in the alteration of frontal sinus ventilation can trapped air, it will get absorbed by the mucosal sinus, and this could cause pain.

From our results, we concluded that the balloon sinuplasty should be considered as a valid alternative option in the treatment of RH. However we emphasize the need of a more accurate selection of surgical candidates; the patients with headache refractory to all other medical treatment should be evaluated not only by neurologist but also by an otorhinolaryngologist and in absence of evident signs of naso-sinusal inflammation a carefully examine and a CT scan should be performed. 


\section{Compliance with Ethical Standards}

Conflict of interest The authors declare that they have no conflict of interest.

Ethical Approval All procedures performed in studies involving human participants were in accordance with the ethical standards of the institutional and/or national research committee and with the 1964 Helsinki declaration and its later amendments or comparable ethical standards.

\section{References}

1. Mitsikostas DD, Ashina M, Craven A, Diener HC, Goadsby PJ, Ferrari MD, Lampl C, Paemeleire K, Pascual J, Siva A, Olesen J, Osipova V, Martelletti P, EHF committee (2015) European headache federation consensus on technical investigation for primary headache disorders. J Headache Pain 17(1):5

2. Cady RK, Schreiber CP (2009) Sinus problems as a cause of headache refractoriness and migraine chronification. Curr Pain Headache Rep 13:319-325

3. Clerico DM (1995) Sinus headaches reconsidered: referred cephalgia of rhinologic origin masquerading as refractory primary headaches. Headache 35:185-192

4. Stammberger H, Wolf G (1988) Headaches and sinus disease: the endoscopic approach. Ann Otol Rhinol Laryngol Suppl 134:3-23

5. Wolff HG (1948) The nasal, paranasal and aural structures as sources of headache and other pain. Headache and Other Head Pain. Oxford University Press, New York, pp 532-560

6. Headache Classification Committee of the International Headache Society (2004) The international classification of headache disorders. Cephalalgia 24(suppl 1):1-160

7. Chow JM (1994) Rhinologic headaches. Otolaryngol Head Neck Surg 111:211-218

8. Clerico DM, Evan K, Montgomery L (1997) Endoscopic sinonasal surgery in the management of primary headache. Rhinology 35:98-102

9. Yarmohammadi ME, Ghasemi H, Pourfarzam S, Nadoushan MS, Majd SA (2012) Effect of turbinoplasty in concha bullosa induced rhinogenic headache, a randomized clinical trial. J Res Med Sci 17(3):229-234
10. Nselmo-Lima WT, de Oliveira JA, Speciali JG, Bordini C, dos Santos AC, Rocha KV (1997) Middle turbinate headache syndrome. Headache 37:102-106

11. Mariotti LJ, Setlif RC, Ghaderi M, Voth S (2009) Patient history and $\mathrm{Ct}$ findings in predicting surgical outcomes for patients with rhinogenic headache. Ear Nose Throat J 88(5):926-929

12. Roozbahany NA, Nasri S (2013) Nasal and paranasal sinus anatomical variations in patients with rhinogenic contact point headache. Auris Nasus Larynx 40:177-183

13. Sanges G, Feleppa M, Gamerra M, Sorrentino G, De Luca R (2011) Fronto-turbinalis sinus expansion and headache. Curr Pain Headache Rep 15:308-313

14. Marzetti A, Tedaldi M, Passali FM (2014) The role of balloon sinuplasty in the treatment of sinus headache. Otolaryngol Pol 68(1):15-19

15. Kuhn FA, Church CA, Goldberg AN, Levine HL, Sillers MJ, Vaughan WC, Weiss RL (2008) Balloon catheter sinusotomy: one-year follow-up-outcomes and role in functional endoscopic sinus surgery. Otolaryngol Head Neck Surg 139(3 Suppl 3):S27S37

16. Levine HL, Sertich AP 2nd, Hoisington DR, Weiss RL, Pritikin J (2008) Multicenter registry of balloon catheter sinusotomy outcomes for 1,036 patients. Ann Otol Rhinol Laryngol 117(4):263-270

17. Greenfield H (1986) A study of referred cephalgia secondary to noxious stimulation of specific regions of nasal mucosa and sinus ostia. In: Presented as scientific exhibitions at the meeting of American Academy of Otolaryngology, San Antonio, Texas, Sept $14-18$

18. Goldsmith AJ, Zahtz GD, Stegnjajic A (1993) Middle turbinate headache syndrome. Am J Rhinol 7:17-23

19. Sluder G (1927) Nasal neurology, headaches and eye disorders. CV Mosby, St. Louis (MO), pp 31-67

20. Bolger WE, Butzin CA, Parson DS (1991) Paranasl sinus bony anatomic variations and mucosal abnormalities: CT analysis for endoscopic sinus surgery. Laryngoscope 101:56-64

21. Roozbahany NA, Nasri S (2013) Nasal and paranasal sinus anatomical variations in patients with rhinogenic contact point headache. Auris Nasus Larynx 40:177-183

22. Kennedy DW (1988) Functional endoscopic approach to inflammatory sinus disease: current perspectives and technique modifications. AM J Rhinol 2:89-96 